\title{
Multifunction of Hedges Used by English Department Students: Gender Role Perspective
}

\author{
Ninis Nur Kholisoh \\ Universitas Negeri Surabaya \\ Surabaya, Indonesia \\ niniskholisoh@mhs.unesa.ac.id
}

\author{
Slamet Setiawan \\ Universitas Negeri Surabaya \\ Surabaya, Indonesia \\ slametsetiawan@unesa.ac.id
}

\begin{abstract}
Hedges are linguistic features that commonly used to lessen the impact of an utterance due to restriction between speakers and interlocutors. Yet, this function might be different depends on the content of conversation and who the speaker is. Some linguists claim that hedges are associated with women's language. However, as a matter of fact, these features also appear in men's speech with different functions, similar to women's one. This study is conducted to examine the presence of possible different functions of hedges and the impact of them toward the interlocutors' responds in the speech of male and female English Department students. To do so, two discussion sessions and a casual interview are done. The finding reveals that there are different types and functions of hedges employed by male and female. Male tends to employ hedges to express uncertainty, selfdisclosure, and politeness while female tends to employ hedges to convey certainty and sustain interpersonal relationship. Moreover, the overuse of hedges creates a bad face of the speaker. The findings suggest that men and women may utilize hedges when communication to represents the state of their mind. However, wise use of these expressions should be considered to avoid negative labels for the speakers.
\end{abstract}

Keywords-hedges; multifunction of hedges; gender role; politeness

\section{INTRODUCTION}

Hedges are linguistic features that get much attention along the years in relation to conversational rules. They are linguistic features that have diverse functions. In daily communication, hedges are commonly employed to show tentative and uncertainty of an assertion [1]. Lakoff [1] claims that hedges are device that employed to soften or add uncertainty to the utterance. Besides, hedges function to lessen the impact of an utterance due to restriction between speaker and interlocutor. Yet, those are not the only function of hedges. Hedges can be used to make the utterance more interesting and more acceptable to the interlocutor [2]. Thus, it will increase the degree of acceptability and minimize the chances of negation. Hedges carry multifunction.

In daily communication, the same hedges can be meant differently. It depends on the content of the conversations and who employs the hedges. The more sensitive topic of the conversation is, the more frequent hedges are used with various functions [3]. In language and gender domain, hedges or other linguistic features that have functions to show tentative also the uncertainty of an assertion are associated and connected to women [1] or too powerless people regardless of their gender [4]. As the pioneer in introducing gender differences in language use, Lakoff [1] claims that hedges are only used by women and are used to show the vagueness of their utterances. Furthermore, Lakoff's finding also believes that hedges are weak in nature and women use these features in their speech without any justification. She further argues that women simply use these features because of their lack of power. However, Lakoff's claim in her finding is just based on her introspection. It shows the weaknesses of methodology she has. Hence, with the notification of this weakness, Lakoff's finding has been challenged by many researchers. Hedges are used by women to show the doubt of their utterance due to they are powerless is not justified [3], [5], [6]. In this concern, Lakoff's finding is criticized and disproved by presenting contradictory finding that women use hedges as the language feature to show their confidence and certainty also politeness [6]. On the other hand, hedges are used by men to show the uncertainty of their utterance. Moreover, the finding of Holmes' study inferred that despite what Lakoff has found, hedges' function is not only to convey the uncertainty and the tentativeness cannot be attached to one gender only. The functions of hedges serve to differ tremendously between genders [6]. Even though hedges are labeled as women's language but they do not rule out the possibility of employing hedges in men's speech.

In fact, on the use of hedges men and women have different kinds of hedges and also different purposes. The different purposes of hedging and kinds of hedges that used by both men and women in their speech will create different impacts and perceptions to the interlocutors' responds. Therefore, the research problem of this study has already mentioned from the phenomenon discussed above. It is about the phenomenon when the male and female speakers hedge their utterances for various purposes. Within this framework, this study is conducted to answer three research questions related to the multifunction of hedges in men's and women's speech, namely: (1) What types of hedges are employed by male and female students? (2) What are the functions of hedges they employ? (3) Are there any serious impacts of using hedges toward the interlocutors' responds? 
In order to answer the three research questions above, this study used some theories as parameters to analyze the data of the use of hedges in conversation which are seen from gender role. The theories are summarized into three points as follows:

\section{a. Hedges and Its Functions}

As human beings, people communicate with each other every day in order to deliver or express their feelings and/or idea. To do so, people often use words or phrases to support their utterances, preserve their face, or even to hide the lack of their knowledge. Every single one needs a feature which can accomplish the utterance. Hedges are the linguistic features that can do those jobs. Hedge is a device that is employed to soften or add uncertainty to the utterance [1]. In addition, it is also defined as words which meaning implicitly involves fuzziness words that makes things fuzzier or less fuzzy [7]. According to another claim, hedging is commonly used by the speakers to show certainty or doubt of their utterances or statements and also it is used to show the confidence toward a claim that they have. A similar definition is offered hedges as a linguistic form that conveys speaker's certainty and uncertainty of the proposition they express [8]. Moreover, some previous studies on this issue have been conducted. One study reveals that hedges are also employed by women as fillers to make time for thinking [9]. On the other side, hedges can be used to make the utterance more interesting and more acceptable to the interlocutor [2]. Thus, it will increase the degree of acceptance and reduce the chances of negation.

In daily communication, the use of hedges and the function of them are influenced by the topics of conversations. The more sensitive the topics get; the more frequent hedges are used [3]. It happens because, in fact, the sensitive topics naturally involve some self- disclosures also face threatening statements, and hedges have a job to help in neutralizing these effects. Besides, hedges' function is also considered by who is the speaker. Different genders may employ different hedges with different functions. All in all, hedges do not have one and the only function. In the world of speaking, we cannot find consensus about the functions that are fulfilled by hedges words.

\section{b. Hedges and Gender}

Men and women are two different speech communities who often live in differences. The existence of the differences between men and women is a perceptible fact that can be observed. In sociolinguistics, men and women have a different way to appeal to the world [10]. Tannen [10] claimed that men consider themselves as individuals who live in the hierarchical social community, while women consider themselves as individuals acting in a network of connections. Those dissimilar orientations toward social communities affect the style of language that employed by men and women. Men and women have contrast linguistic behavior, it is claimed that women are more linguistically polite, highly structured, and dramatic than men [11]. In order to highlight the differences style of language employed by different gender, a term women's language was offered by Lakoff [1]. Hedges is one of the features of women's language that often used by both men and women in their daily communication. As stated earlier, hedges are linguistic features that associated with women and considered as women's language. Furthermore, it is seen in women's interaction more than men's mainly because of the cooperative nature that hedges carry [4], [5], [12]. Hedges that employed by men and women have the possibility to have a different function. Women employed hedges to express their confidence and certainty in their knowledge, while men employed them to convey and indicate uncertainty about their utterance [5], [6]. There are several studies which prove that there are no significant differences in the use of hedges between men and women [6], [13]. However, the function of these features may serve to differ tremendously between genders [6].

\section{c. Taxonomy of hedges}

The taxonomy of hedges provided by Salagar-Mayer was employed for the analysis of the transcriptions [15]. The taxonomy consists of seven main categories, namely:

1. Modal auxiliary verbs: e.g. may, can, would, should, etc.

2. Modal lexical verbs: These are speech act verbs mostly employed to reveal one's doubt and evaluation: e.g. to indicate, to believe, to appear, to suggest, to assume, to seem, etc.

3. Adjectival, adverbial, and nominal modal phrases: a) probability adjectives: e.g. probable, possible, b) nouns: e.g. assumption, possibility, claim, c) adverbs: e.g. presumably, perhaps, probably, likely, possibly.

4. Approximates of degree, quantity, frequency, and time: e.g. about, approximately, usually, roughly, generally, often.

5. Introductory phrases: e.g. it is our view that, to our knowledge, I believe, I think, we feel that.

6. If clauses: e.g. If true, if anything

7. .Compound hedges: Salagar-Mayer distinguishes double hedges (it may suggest), treble hedges (it seems reasonable to assume that) and quadruple hedges (it would seem somewhat unlikely that)

Besides, those kinds of hedges above, there are several additional kinds of hedges that proposed by Lakoff [1] such as you know, sort of, well, you see.

\section{METHOD}

\section{A. Participants}

To accomplish the objective of this study, four students of two males and two females from English Department of UNESA (State University of Surabaya) are chosen as the subjects. To address the homogeneity, it should be mentioned that all the participants are at the same level of speaking proficiency, namely level 6 (from 7 levels) of English Speaking Community (ESC). Moreover, they are all in the fifth semester. Hence, it can be concluded that all the participants hold the same level of proficiency and the same competence. 


\section{B. Data Collection Procedure}

\section{1) Discussion groups}

Two sessions discussion with multi-gender context were held to examine all the possible different functions of hedges within different gender perspectives. Each of session consists of 1 male student and 1 female student. Participants in the same discussion session are considered as one group.

\section{2) Discussion topics}

In order to get a conversation as natural as possible, five topics in the form of questions were given. It was done because some researchers believe that males' and females' language may be affected by the selected topics [14]. The topics were given to the participants with two considerations. First, they are related to the final exam preparation for the fifth semester as this research was conducted in two weeks before the final exam. Second, those topics are considered to be the representation of student's psychological state as at that time most of the fifth semester students of English Department were stressful because of overload assignments. So, those topics are considered as the suitable topic that could make all the participants speak freely, enjoy the discussion, have lot ideas about anything that they wanted to say, and also those topics could create a warm atmosphere. Hence, this discussion would result in a natural conversation as expected.

\section{3) Discussion sessions}

To examine the types and functions of hedges that were used by males and females, the discussion section was recorded. The participants were asked for permission to record their voices. Yet, the main objectives of this study were not explained in order to avoid the effect of participants' possible biases in their use of hedging devices. Moreover, in order to get the most natural data, participating observation is conducted by taking part in conversation and discussion. Each discussion lasted fifteen minutes and the overall amount of recorded discussion is thirty minutes for two groups/sessions.

\section{4) Casual interview}

To examine the impact of the use of hedges toward the interlocutors' responds, a casual one to one interview was held. Each participant was asked his/her responds toward the way his/her interlocutors discussed the topics and also conveyed his/her ideas. In order to make sure that the participants answered the proper questions, some clues were given to the participants, such as: Did you enjoy the discussion? Do you like the way he/she talks? Did you feel annoyed with the words such as I think, well, you know, etc. that he/she used to convey his/her idea? What do you think about those kinds of words? Can you guess his/her reason why he/she used that word?

\section{RESULT AND DISCUSSION}

To analyze the data of this finding, the table below is served to depict the kinds and the multifunction of hedges used by men and women in their speech.
TABLE I. TYPES AND FUNCTIONS OF HEDGES IN MEN' AND WOMEN' SPEECH

\begin{tabular}{|c|c|c|}
\hline & Male students & Female students \\
\hline $\begin{array}{l}\text { Types of } \\
\text { hedges }\end{array}$ & $\begin{array}{l}\text { - Introductory phrases } \\
\text { hedging (I know) } \\
\text { - Lexical hedges (you } \\
\text { know) } \\
\text { - Modal auxiliary (maybe) }\end{array}$ & $\begin{array}{ll} & \text { Introductory phrases } \\
\text { hedging (I know) } \\
\text { - } \\
\text { Lexical hedges (you } \\
\text { know) } \\
\text { - } \text { Modal auxiliary (may) } \\
\text { - Adverbial modal } \\
\text { phrases (likely) } \\
\end{array}$ \\
\hline $\begin{array}{c}\text { Functions of } \\
\text { hedges }\end{array}$ & $\begin{array}{l}\text { - Self-disclosure } \\
\text { - Making utterance fuzzier } \\
\text { - As filler } \\
\text { - Approaching } \\
\text { interlocutors' attention } \\
\text { - Politeness }\end{array}$ & $\begin{array}{l}\text { - Uncertainty } \\
\text { - Strong belief } \\
\text { - Establishing and } \\
\text { sustaining } \\
\text { interpersonal } \\
\text { interaction } \\
\text { - Making utterances less } \\
\text { fuzzy } \\
\text { - As filler }\end{array}$ \\
\hline
\end{tabular}

It can be seen in Table I, the finding reveals that, first, men and women employed almost the same kinds of hedges in their speech. However, those kinds of hedges carry different functions. Men often employed hedges to express uncertainty, fuzziness, and self-disclosure. Besides, men's hedges were to show their politeness. On other hand, women often used hedges to covey the certainty, strong belief, and also to establish and sustain the interpersonal relation between speaker and interlocutor. Table I also presents the fact that hedges carry various functions in discussion sessions. One type of hedges carries more than one functions based on the topic of discussion and gender of the speaker. The male student employed introductory phrases hedging at most to convey uncertainty, self-disclosure, and politeness. While women often used a modal auxiliary verb to convey certainty and build up also strengthen the interpersonal relationships.

Second, the use of hedges in discussion sessions affects the respond of interlocutors toward the speaker. Some said that the use of hedges did not really give a big impact in discussion; even it made the discussion more interesting. Yet, some confessed that the overuse of hedges in a discussion was annoying and ravage the situation. Moreover, the overuse of hedges can depict the personal character of the speaker and the knowledge of a speaker. Hence, those factors did affect the interlocutor to respond to the speaker's utterance and also affect the atmosphere of the discussion.

This study shows that both men and women employed hedges in their speech with the aim to support their utterances. Moreover, regardless of the gender, the participants employed several different types of hedges and for different purposes. This finding conveys that hedges employed by men carry more various functions than women do. Hence, this finding disproves the claim of the previous study by Lakoff [1] who states that hedges is associated with women and always indicated with the function as the linguistic feature to show uncertainty or doubt. Therefore, to answer the three research questions above the findings of this study are explained in turns below. 


\section{1) Male students}

a. I think (Introductory phrases)

I think is one of the kinds of introductory phrase hedging that often appears in male students' speech. They employed these hedges more than five times for each discussion. Moreover, these kinds of hedges carry various functions on male students' speech.

\section{- Self-disclosure}

I think can be meant as self-disclosure when the conversation gets personal and the speakers want to disclose their feelings. This following example in (01) demonstrates this claim.

\section{(01) R : So far, does this semester become your best semester or the worst one? \\ $\mathrm{F} 1$ : \\ M1 : I think this is the hardest semester because /e:::/ Mr. X said that I can't join the exam /o:::/ because of my attendance list, so this my first time I can't join the exam and I will do my best (inhaling deeply). But about the assignment is a little bit harder but as long as we can handle that it's okay.}

In conversation presented in (01), Male speaker 1 (henceforth M1) talked about his fifth semester. M1 tried to express his opinion that this semester was harder for him due to a certain reason by using the hedge of I think... This hedge is categorized as introductory phrases. Moreover, on describing how sad and overwhelming he was in that semester he took a deep breath. However, by employing the words but at the end of his utterance, he tried to decrease the sensitiveness of his self-disclosure. Moreover, the words but which were said twice to emphasize the main factors that made that semester become harder for him. In addition, those words implicitly stated that assignments do not the matters of his sadness.

All those features and his behavior (inhaling deeply) after self-disclosed reveals his sadness about his confession. The reason lies in the fact that men are expected to suppress his feeling rather than express them [16]. This citation clearly demonstrates how M1 uses hedges to protect his face.

- Making fuzziness and filler

To start with, study the following dialog in (02).

(02) R
$\mathrm{R}$
So far, does this semester become your best semester or the worst one?
M2 : I think I don't know, it just like you know it just like a previous semester because ..........., we can finish it I think that's all....

In (02), the Male speaker 2 (henceforth M2) described his opinion and his feeling about this semester. Yet, by hedging his utterance, it made his utterance above contains a lot of fuzziness. He started his speech by hedging his personal opinion and used introductory phrases hedging I think. However, after he hedged his personal idea, he made his utterance fuzzier by saying I don't know. It seems he wanted to claim something but he did not know how to declare it. Moreover, he used lexical hedges you know as the filler to make time for thinking. Then, in the last of his statement he used the word I think to emphasize his utterance and tried to say that all he said before was only his own opinion and he did not insist anybody agree with his opinion. The utterance of M2 pragmatically means nothing because what he said is full of fuzziness. This reason justified by Lakoff [7] who defined hedges as words which meaning implicitly involves fuzziness words which job is to make things fuzzier or less fuzzy.

\section{b. May be (Modal auxiliary)}

In the conversation that was observed for this study, modal auxiliary hedging (may be) did not too frequently appear in male students' speech. However, it still appears rarely by carrying several different functions. The discussion is presented below.

\section{- Uncertainty}

Uncertainty is the common function of hedges that is often employed by people in conversation. An utterance can be defined as uncertainty when the speakers are not pretty sure about what they are talking. In other words, there is an overwhelming state inside their utterances. Conversation in (03) is an instance where the speaker uses hedges to show his uncertainty about their assertions. Nevertheless, besides expressing uncertainty, the hedges in question convey other functions as well.

(03) F1

M2 : I think I don't know, it just like you know it just like a previous semester because maybe we just complain about the assignment and something like that but finally we face this semester and until the end we can do it. So, /yaa/ maybe the assignment will be harder than before but/but/ finally we can do this, we can finish it $I$ think that's all....

In (03), M2 was talking about his opinion and feeling for this fifth semester. In the very first of his utterance he used hedges to convey fuzziness I think and as the filler you know then continued by hedging his opinion may be. Through this utterance, he stated that this semester was like the previous one. However, by employing some hedges while expressing his opinion, he seems not really sure if the present semester and previous one were the same.

Then, the hedges in the second utterance So, yaa maybe the assignment... once again M2 shows the uncertainty of his assertion. He was not really sure whether the assignment in the fifth semester would be harder. Yet, in fact, he said it was harder. Besides, M2 also tried to preserve his face to his interlocutor/s by hedging his utterance in order to make it wiser.

\section{c. You know}

According to Lakoff [1], the word You know is also one of the hedges. This expression also functions as filler. The surprising finding is revealed in this study in which male students use this for different functions. Besides, this kind of hedge is used most frequently by male students. The evidence of this phenomenon is described below. 
- Approaching attention and politeness

Study the conversation in (04).

(04) F2: $: \ldots$.

M2 : I am not interested at all to continue my study because you know aa study is a must but money more than must. So I just help to find a work I have find I a job I have to be like you know $\mathrm{S} 1$ is just aa is more than enough you know and yaa may be if your dad insists you to continue your study yaa just go on (laughing).

In (04), M2 talked about his opinion of continuing study. He tried to convey that he was not willing to continue to study in the next degree. Then he hedged his opinion by using words you know in "... you know aa study is a must but money more than must...". This hedge was used to approach the interlocutor's attention to make them focus on his claim which is suitable with the fact; money is more important than study. The second hedge you know was used to show his politeness. His said "...you know S1 is just aa is more than enough you know..." can be heard insane for some people who really are strict in education, so he hedged his claim to make it sounds politer. Then to make his claim sound politer and neutral, he hedged it once gain by using maybe if as in "...may be if your dad insists you to continue your study yaa just go on (laughing)". By hedging his claim once again he tries to neutralize the effect of the sensitiveness of this topic [3]. Besides, by hedging his claims he tries to save his face.

\section{2) Female students}

\section{a. I think (Introductory Phrases)}

In this study, this kind of hedges is used by female students at most. They often hedge their utterances by using this with several functions. Here are the instances.

\section{- Uncertainty}

There is an example which shows the function of hedges as conveying uncertainty of an utterance. However, besides expressing uncertainty, they convey other functions. Study the conversation in (05).

(05) M2 :

F2 : Uhh I think it called the worse thing is because the process to do the assignment, emm ............So, some of this assignment according to our knowledge only emm most of the subject I think.

In (05), the Female speaker 2 (henceforth F2) was talking about the reason why this semester become her worse semester. She started her claim by hedging her personal idea using I think as to guest factor that might be responsible for making her worse semester. This hedge is employed because she is not really sure about the true factors of it. The factor is uncertain. Besides, she also tried to hold neutral position by making a general claim.

\footnotetext{
- Strong belief

(06) M2 : $\quad \ldots \ldots$...

F2 : But $I$ think Bobi is also right because Bobi said that about it's about us also. We used to complain about the assignments and /aaa/. So, the assignment will be hard heavy.
}

The hedge in (06) I think in the very start of F2' speech shows that the speaker F2 was agreeing to the claim of her interlocutor (Bobi) about this fifth semester. She hedged it in order to put the strong belief toward her interlocutor's claim. Moreover, by hedging her utterance she also tries to build up better relationship with her interlocutor [17].

\section{b. May be (Modal auxiliary) \\ - Uncertainty}

(07) F1 : I don't know, for me I don't know the result of this fifth semester that's why I can't say that this will be the worse semester but maybe (stop talking and disturbed by other)

The Female speaker 1 (henceforth F1) was trying to convey and describe this fifth semester. To do so, she hedged her utterances by using modal auxiliary may be to convey the uncertainty. Through her utterance, it can be detected that the speaker did not really sure and know whether this semester was her better semester or the worse one. So, she used this linguistic feature to convey the uncertainty. Moreover, she also hedged her utterance to hold neutral position by delivering general claim.

\section{- Establishing and sustaining interpersonal relations}

(08) W1: Maybe Bahrul because I know that he used to /emm/ write the sticky note to do the assignment.

F1 in (08) did hedging at the very first of her utterance to establish and sustain interpersonal relation between her and her interlocutor who is a male student. She tried to invite her interlocutor to share her strategy to manage the assignment. She also did so in order to build up a more interactive conversation. In addition, she tried to preserve her face.

\section{c. Likely (Adverbial Modal Phrase) \& You know \\ - Making utterance less fuzzy and as filler}

(09) F1 : Yesterday I also likely I got drunk. I just too much thinking about the assignment. I just like you know ngomong Yaa Allah soroe urip iki like that (Javanese language).

In (09), F1 was expressing her feeling about this fifth semester, especially about the assignments. She hedged her utterance by using adverb likely to diminish the strength of word drunk that contains fuzziness. Then, in the next utterance, she used the word you know as filler that shows the lack of knowledge.

3) Impact of hedges toward the response of interlocutor

Soon after each discussion session with male and female participants of this study, a casual interview is held. This is held with the aim to examine the impact of using hedges toward the response of the interlocutor. The result of the 
interview reveals that the use of hedges affects the response of the interlocutor toward the utterances that speakers said. It also allows the interlocutors to evaluate the participants' speaking ability on the discussion. The more hedges they employed, the bigger impact they would get. Most of the participants of this study can tolerate the use of hedges in normal number like 1-2 times in one utterance. Some of them believe that hedges can bridge us to create good communication and interpersonal relationship. However, if hedges employed in over amount such as more than 3 times in one utterance, most of them considered it as annoying. In a coincidence, in the second discussion session, one of the male participants of this study (M2) is a one who employed hedges at most in his speech. He often employed introductory hedges (I like) and you know in almost his utterances. To know the impact of this overuse hedges, his interlocutor was asked about her response. According to the interlocutor (F2), the use of hedges at the beginning of the discussion did not really give big impact to her. Yet, when discussion runs in half duration she felt annoyed with the hedges that M2 employed. She said that M2 had lack of knowledge and lack of vocabularies for doing a discussion and seems arrogant. On the other side, the first team in first discussion session did not have any serious impact on employing hedges in speech since the speaker did not overuse hedges. Hence, this finding may suggest that the use of hedges does affect the response of the interlocutor. The more hedges are employed; the more impact will be created.

\section{CONCLUSION}

To recap, this study rejects the claim of the previous study by Lakoff [1] who claims that hedges are only used by women and they are used to show the vagueness of their utterances. This study reveals that male students use more hedges then female ones. Furthermore, male students also employ more various kinds of hedges and have different functions with the hedges that female students do. The finding also reveals that men employ hedges in their speech more frequently than women for various functions such as expressing uncertainty, self-disclosure, and politeness. Furthermore, they use introductory phrases hedging at most to reach those various purposes. On the other hand, female students more often employ modal auxiliary hedging with various purposes such as conveying certainty and establishing also sustaining interpersonal relation between speaker and interlocutor. The findings, therefore, does not justify the claim of Lakoff [1] who associates hedges to women and claims their function is to convey doubt and uncertainty of women's utterances due to their powerless. Moreover, this study justifies the previous study by Holmes [6] who argues that women use hedges as the language feature to show their confidence and certainty while men employ hedges to convey uncertainty of their utterances. Conveying uncertainty and tentativeness as the function of hedges cannot be attached to one gender only. The functions of hedges serve to differ tremendously between genders [6].

\section{REFERENCES}

[1] T. R. Lakoff, Language and Woman's Place. New York: Harper \& Row, 1975.

[2] A. Hübler, Understatements and Hedges in English. Amsterdam: John Benjamins Publishing Company, 1983.

[3] J. Coates and P. Pichler, "'Gossip revisited: Language in all-female groups (Coates, J. )' in Language and gender: a reader," in Language and gender: a reader, 2 nd ed., J. Coates and P. Pichler, Eds. Chichester, West Sussex, U.K.: Wiley-Blackwell, 2011.

[4] B. K. O'Barr, W., Atkins, “'Women's language' or 'powerless language'?," in Language and gender: A reader, J. Coates., United Kingdom: Wiley-Blackwell, 2011, pp. 451-460.

[5] J. Holmes, "Hedging your bets and sitting on the fence: Some evidence for hedges as support structures," Te Reo, vol. 27, no. 1, pp. 47-62, 1984.

[6] J. Holmes, "Functions of you know in women's and men's speech," Lang. Soc., vol. 15, no. 1, pp. 1-22, 1986.

[7] T.R. Lakoff, A Study of Meaning Criteria and The Logic of Fuzzy Concept. Chicago: Chicago University Press, 1972.

[8] J. Coates, Women, men, and language: A sociolinguistic account of gender differences in language, 3rd ed. 2004.

[9] H. Section, S., Amir, Z., Abidin, "Gender Differences in The Language Use of Malaysian Teen Bloggers," vol. 12, pp. 105-124, 2012.

[10] D. Tannen, You just don't understand. New York: Ballantine, 1990.

[11] J. Holmes, Learning About Language. 2001.

[12] J. Coates, Epistemic modality and spoken discourse.Transactions of the Philological Society. 1987.

[13] E. T. Vold, "Epistemic modality markers in research articles: A crosslinguistic and cross-disciplinary study," Int. J. Appl. Linguist., vol. 16, no. 1, pp. 61-87, 2006.

[14] S. L. Brown, C.E., Dovido, J.F., Ellyson, "Reducing Sex Differences in Visual Displays of Dominance: Knowledge is power," Personal. Soc. Psychol. Bull., vol. 16, no. Reducing Sex differences in visual displays of dominance, pp. 358-368, 1990 .

[15]F. Salager-Meyer, "I Think That Perhaps You Should: A Study of Hedges in Written Scientific Discourse," in T. Miller (Ed.), Functional Approaches to Written Text: Classroom Applications, Washington, D.C: English Language Programs-United States Information Agency, 1997, pp. $105-118$.

[16] M. Kaufman, "Men, Feminism, and Men 's Contradictory Experiences of Power," in A. Minas (Ed.,), Gender basics: Feminist perspective on women and men, 2nd ed., 2000, pp. 23-29.

[17]M. Dousti, "ELT Students ' Gender Differences in the Use of Hedges in Interpersonal Interactions: A Mixed Method Approach Applied," vol. 3 , no. 1 , pp. $217-231,2016$ 